\title{
PHASE TRANSITION, DIELECTRIC RELAXATION AND IMPEDANCE SPECTROSCOPY OF PEROVSKITE $\mathrm{xBa}_{0.95} \mathrm{Sr}_{0.05} \mathrm{TiO}_{3}-(1-\mathrm{x}) \mathrm{BiFe}_{0.9} \mathrm{Sm}_{0.1} \mathrm{O}_{3}$ CERAMICS
}

\author{
M. J. MIAH ${ }^{*}$, S. C. MAZUMDER ${ }^{1}$ AND A. K. M. AKTHER HOSSAIN ${ }^{2}$ \\ ${ }^{1}$ Department of Physics, Comilla University, Bangladesh \\ ${ }^{2}$ Department of Physics, Bangladesh University of Engineering and Technology, Bangladesh \\ *Corresponding author e-mail: mmjulhash@yahoo.com
}

Received on 12.03.2020, Revised received on 12.06.2020, Accepted for publication on 18.06.2020

DOI: https://doi.org/10.3329/bjphy.v27i1.49724

\begin{abstract}
Polycrystalline $\mathrm{xBa}_{0.95} \mathrm{Sr}_{0.05} \mathrm{TiO}_{3}-(1-\mathrm{x}) \mathrm{BiFe}_{0.9} \mathrm{Sm}_{0.1} \mathrm{O}_{3}[\mathrm{xBST}-(1-\mathrm{x}) \mathrm{BFSO}]$ ceramics were synthesized. The structural phase transitions were studied and it was found that structure of the compound transformed from rhombohedral to cubic phase. The compound exhibited a dielectric anomaly in the vicinity of Néel temperature of $\mathrm{BiFeO}_{3}$ except for $\mathrm{x}=0.25$. Enhanced dielectric properties were noticed and this might be attributed to the reduction of oxygen vacancies. Studies of electrical conductivity over a wide temperature range showed that the ceramics behaved like a semiconductor with the negative temperature coefficient of resistance. Contribution of grains in conduction mechanism of the materials dominated and the grain resistance was found to be decreased with the increase in temperature. A Non-Debye type relaxation was seen in the material. The impedance data were re-plotted using the modulus formulae to avoid the ambiguity arising out of the presence of grain/grain boundary effect. Activation energy was found to be 0.18 to $0.33 \mathrm{eV}$ in modulus study which was very close to complex impedance observation and it was implied that the charge carrier had the same energy barrier during the relaxation.
\end{abstract}

Keywords: Phase transition; Dielectric relaxation; Complex impedance; Activation energy.

\section{INTRODUCTION}

A great revolution in the field of science and technology has created due to the discovery of multiferroic properties in single phase or in composite materials. It resulted in the development of a wide range of new multifunctional compounds useful for commercial applications and research. They have the use in transducer, sensors, optical fiber, random access memory, electrically controlled microwave phase shifters etc. [1]. Materials based on bismuth ferrite $\mathrm{BiFeO}_{3}(\mathrm{BFO})$ and the solid solution of $\mathrm{BFO}$ with other ferroelectric perovskites is dominating among the multiferroics.

Among multiferrioc materials BFO is only one candidate which exhibits multiferrioc properties at and above room temperature [2]. It has an antiferromagnetic Néel temperature $\left(\mathrm{T}_{\mathrm{N}}\right)$ at $370^{\circ} \mathrm{C}$ and a high ferroelectric Curie temperature $\left(\mathrm{T}_{\mathrm{C}}\right)$ at $830{ }^{\circ} \mathrm{C}$ [3]. But the use of $\mathrm{BFO}$ is very limited because of its some serious drawbacks such as large leakage current with applied electric field, poor dielectric properties, weak magnetic behavior and poor phase stability $[2,4]$. In order to improve the properties solid solution of BFO with other ferroelectric materials is well established and many articles have been published on the compositions of $\mathrm{BFO}-\mathrm{BaTiO}_{3}(\mathrm{BFO}-\mathrm{BT})$ [5], $\mathrm{BFO}-\mathrm{PbTiO}_{3}(\mathrm{BFO}-\mathrm{PT})$ [6], BFO-BiNaTiO ${ }_{3}$ (BFO-BNT) [7] etc. 
The BFO-BT ceramics have perovskite $\mathrm{ABO}_{3}$ structure $(\mathrm{A}=$ mono or divalent, $\mathrm{B}=$ tri-hexavalent ions) in which $\mathrm{A}$-site is occupied by $\mathrm{Bi}^{3+}$ and /or $\mathrm{Ba}^{2+}$ ions and the $\mathrm{B}$-site is occupied by $\mathrm{Fe}^{3+}$ and/or $\mathrm{Ti}^{4+}$ ions. The impurity phases that are observed in BFO are found to be disappeared when BT is mixed with BFO because of speed up the formation of kinetics. It exhibits improved magnetic as well as electric properties and also it shows relaxor behavior [8-10]. Several studies have been performed on the effect of substitution in A-site by alkaline earth metals, rare earth elements, alkali etc. [11-15] and in B- site by transition metals [16, 17]. But substitution of A- site by alkaline earth metals and B- site by rare earth element simultaneously is rare. Multiferroic properties of the solid solution $\mathrm{xBa}_{0.95} \mathrm{Sr}_{0.05} \mathrm{TiO}_{3}-(1-\mathrm{x}) \mathrm{BiFe}_{0.9} \mathrm{Gd}_{0.1} \mathrm{O}_{3} \quad$ [xBST-(1-x)BFGO] and $\mathrm{xBa}_{0.95} \mathrm{Sr}_{0.05} \mathrm{TiO}_{3}-(1-$ $\mathrm{x}) \mathrm{BiFe}_{0.9} \mathrm{Dy}_{0.1} \mathrm{O}_{3}$ [xBST-(1-x)BFDO] have been revealed in our previous literatures [18, 19]. It has shown that overall properties were improved due to the modification of BT-BFO solid solution by $\mathrm{Sr}^{2+}$ ions in Ba- site and $\mathrm{Fe}$ - site by the rare earth elements $\left(\mathrm{Gd}^{3+}, \mathrm{Dy}^{3+}\right)$. The rare earth element Samarium $\left(\mathrm{Sm}^{3+}\right)$ also satisfies the basic requirements for its substitutions to perovskite elements such as stability of perovskite phase, suitable ionic radius $(\sim 0.96 \AA)$, high Cuire-Weiss temperature $\left(696{ }^{\circ} \mathrm{C}\right)$ usually required for the ferroelectric memory devices etc. The detail study of structural and electrical properties (dielectric phenomenon, conduction behavior, electrical relaxation process etc.) of $\mathrm{xBa}_{0.95} \mathrm{Sr}_{0.05} \mathrm{TiO}_{3}-(1-\mathrm{x}) \mathrm{BiFe}_{0.9} \mathrm{Sm}_{0.1} \mathrm{O}_{3}$ [xBST-(1-x)BFSO] compositions have been reported using complex impedance spectroscopy (CIS) technique in this paper. Electric conduction in polycrystalline materials is involved from grains, grain boundaries and electrode-specimen interface [20, 21]. CIS technique assists us to separate the contribution of grain, grain boundaries and electrode in a convenient way. The effect of temperature and frequency in conduction mechanism has also been illustrated in this article.

\section{EXPERIMENTAL PROCEDURE}

\subsection{Sample preparation}

$\mathrm{xBa}_{0.95} \mathrm{Sr}_{0.05} \mathrm{TiO}_{3}-(1-\mathrm{x}) \mathrm{BiFe}_{0.9} \mathrm{Sm}_{0.1} \mathrm{O}_{3}$ [xBST-(1-x)BFSO] $(\mathrm{x}=0.00,0.10,0.20,0.25,030$ and 0.35) ceramics were prepared by the conventional solid state reaction technique. Raw materials of $\mathrm{BaCO}_{3}(99.9 \%), \mathrm{SrCO}_{3}(99.9 \%), \mathrm{TiO}_{2}(99.9 \%), \mathrm{Bi}_{2} \mathrm{O}_{3}(99.9 \%), \mathrm{Fe}_{2} \mathrm{O}_{3}(99.9 \%)$ and $\mathrm{Sm}_{2} \mathrm{O}_{3}(99.95 \%)$ were mixed according to the stoichiometric formula and ball-milled in distilled water for $24 \mathrm{~h}$ to increase the degree of mixing. Mixture of the above-mentioned raw materials were calcined at 850 ${ }^{\circ} \mathrm{C}$ for $1 \mathrm{~h}$. The calcined powders were ground thoroughly and to obtain homogeneous mixture the powders were ball-milled again. Then $10 \%$ polyvinyl alcohol (PVA) was mixed as a binder for granulation. Disk and toroid- shaped samples were made using these powders with a uniaxial press at $145 \mathrm{MPa}$ pressure. Finally, the green pellets were sintered at $900{ }^{\circ} \mathrm{C}(\mathrm{x}=0.00), 950{ }^{\circ} \mathrm{C}(\mathrm{x}=0.10$, 0.20 and 0.25$)$ and $1000{ }^{\circ} \mathrm{C}(\mathrm{x}=0.30$ and 0.35$)$ for $1 \mathrm{~h}$ respectively.

\subsection{Characterization}

The phase formation and crystal structure of the samples were characterized by using an X-ray diffractometer (XRD) (Philips PANanalytical X'PERT-PRO) with a $\mathrm{Cu}$ anode $\left(\mathrm{CuK}_{\alpha}\right.$ radiation source with $\lambda=1.541 \AA$ ) at room temperature and $1^{\circ} \mathrm{min}^{-1}$ scanning speed, by collecting the data in a $2 \theta$ range of $20-60^{\circ}$. The value of lattice parameters was determined from the XRD data.

The various electrical parameters were carried out in the temperature range of $30-450{ }^{\circ} \mathrm{C}$ with the frequency range of $1 \mathrm{kHz}-1 \mathrm{MHz}$ by using a WAYNE KERR 6500B Impedance Analyzer. To 
measure electric properties the samples were painted by conducting silver paste on both sides to ensure good electrical contacts. After electroding, the samples were dried at $150{ }^{\circ} \mathrm{C}$ to remove moisture. The dielectric constant $\left(\varepsilon^{\prime}\right)$ was calculated from the capacitance using the formula: $\varepsilon^{\prime}=\frac{C d}{\varepsilon_{0} A}$ $\varepsilon_{0}\left(=8.85 \times 10^{-12} \mathrm{~F} / \mathrm{m}\right)$ is the permittivity in free space. The AC conductivity $\left(\sigma_{\mathrm{AC}}\right)$ was calculated using the relation: $\sigma_{\mathrm{ac}}=\omega \varepsilon^{\prime} \varepsilon_{0} \tan \delta$, where, $\omega$ is the angular frequency and tan $\delta$ is the dielectric loss.

\section{RESULTS AND DISCUSSION}

\subsection{Structural analysis}
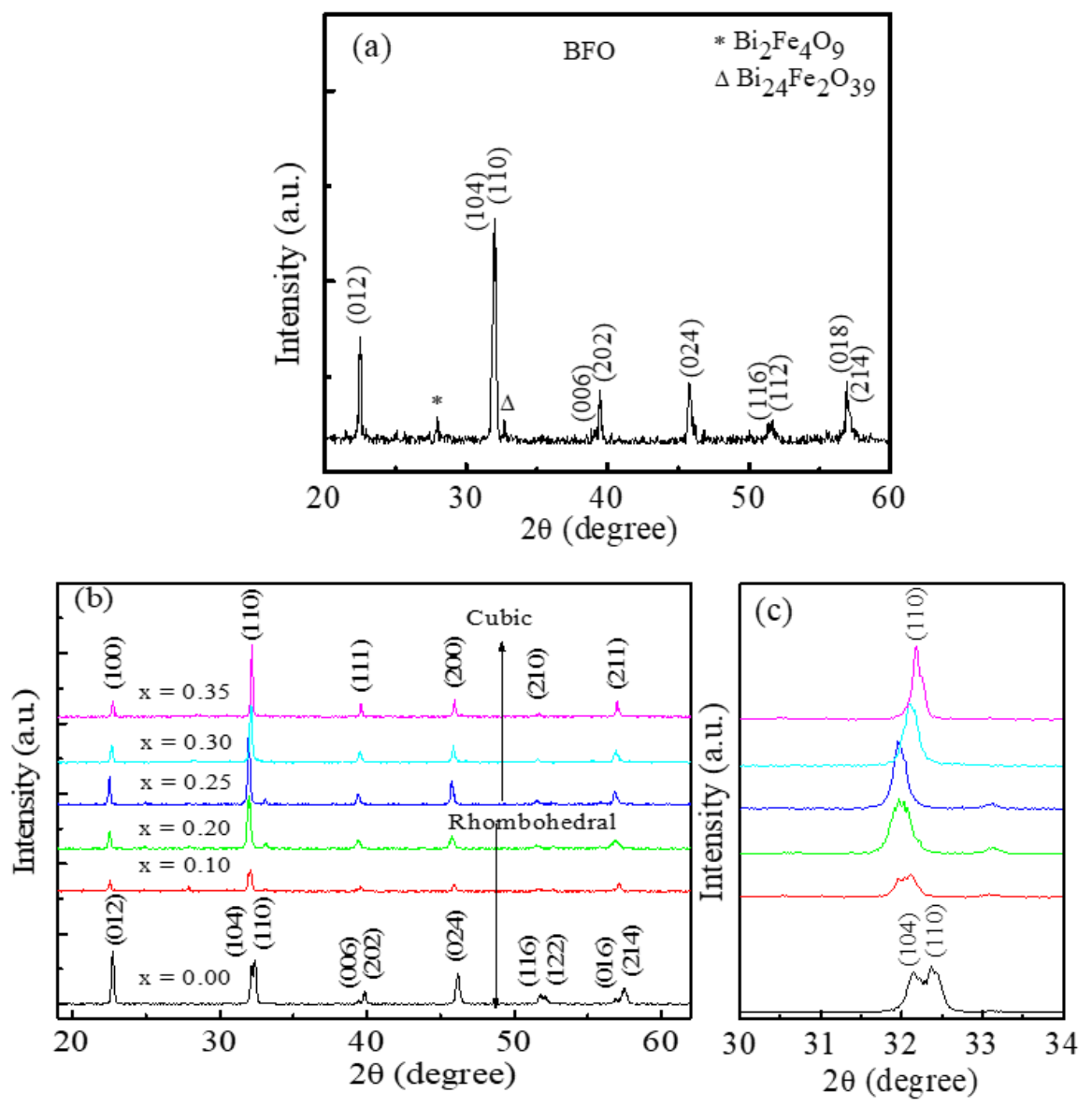

Fig. 1. XRD pattern of (a) BFO, (b) various xBST-(1-x)BFSO ceramics and (c) enlarged view of (110) peak for different compositions. 
Fig. 1(a) and (b) show the XRD patterns of BFO and various xBST-(1-x)BFSO (where, $x=0.00$, $0.10,0.20,0.25,0.30$ and 0.35 ) ceramics respectively. Rhombohedrally distorted perovskite structure of BFO is seen in XRD pattern with two impurity peaks indicated by * and $\Delta$. The position of all peaks of XRD patterns of various XBST-(1-x)BFSO ceramics have been fitted with the earlier report of xBT-(1-x)BFO system [22]. Moreover, the impurity peaks observed in the XRD pattern of BFO (Fig. 1(a)) are found to be disappeared for the case of xBST-(1-x)BFSO ceramics which indicate that BST helps to accelerate the phase formation kinetics of xBST-(1-x)BFSO ceramics. A slight change in the position of XRD peaks is noticed with the addition of BST. The peaks shift towards the lower angle side up to $\mathrm{x}=0.20$ and after $\mathrm{x}=0.20$ the peaks move towards the higher angle side. The shifting of XRD peaks indicates a transformation of crystal structure with the addition of BST in XBST- $(1-x)$ BFSO solution. All peaks of the XRD pattern are indexed matching with the previous records of perovskite systems [23, 24]. The results show that the crystal structure is close to rhombohedrally distorted perovskite up to $\mathrm{x}=0.20$ and then it transforms to cubic structure for $\mathrm{x}$ $=0.25$ to 0.35 . Fig. 1 (c) shows the enlarged view of the most intense peak (110) which also suggests the transformation of crystal structure from rhombohedral to cubic. The results are consistent with previously reported xBT-(1-x)BFO system $[25,26]$.

The value of lattice parameters $(a$ and $c$ ) for rhombohedrally distorted perovskite structure are determined using the formulae of hexagonal equivalent [23]. The values are found to $b e \mathrm{a}=\mathrm{b}=5.52$ to $5.60 \AA$ and $\mathrm{c}=13.44$ to $13.57 \AA$. The lattice constant ' $\mathrm{a}$ ' for cubic structure is varied from 3.94 to $3.92 \AA$. Table 1 shows the value of lattice parameter for all compositions. The lattice parameters ' $\mathrm{a}$ ' and ' $\mathrm{c}$ ' for rhombohedral structure increase with the addition of BST content which follows Vegard's law [27]. On the other hand, the lattice constant 'a' for cubic phase slightly decreases.

\subsection{Tolerance factor}

A distortion in perovskite structure is found to be occurred because of mismatch in ionic radius of cations, which includes the tilting of oxygen octahedra. The distortion of the structure is determined by the calculation of tolerance factor ' $\mathrm{t}$ ' given by Eq. (1),

$$
t=\frac{R_{A}+R_{O}}{\sqrt{2}\left(R_{B}+R_{O}\right)}
$$

where, $R_{A}, R_{B}$ and $R_{O}$ are the ionic radii of A-site, $B$-site cations and oxygen, respectively which was introduced by Goldschmidt [28] in 1926. For the case of $\mathrm{xBa}_{0.95} \mathrm{Sr}_{0.05} \mathrm{TiO}_{3}-(1-\mathrm{x}) \mathrm{BiFe}_{0.9} \mathrm{Sm}_{0.1} \mathrm{O}_{3}$ compound Eq. (1) can be written as :

$$
t=\frac{(x) 0.95 . R_{B a^{2+}}+(x) 0.05 . R_{S^{2+}}+(1-x) R_{B i^{3+}}+R_{O^{2-}}}{\sqrt{2}\left[(x) R_{T^{4+}}+(1-x) 0.9 \cdot R_{F^{3+}}+(1-x) 0.1 . R_{S m^{3+}}+R_{O^{2-}}\right]}
$$

where, $R_{\mathrm{Ba}^{2+}}, R_{\mathrm{Sr}^{2+}}, R_{\mathrm{Bi}^{3+}}, R_{\mathrm{Ti}^{4+}}, R_{\mathrm{Fe}^{3+}}, R_{\mathrm{Sm}^{3+}}$ and $R_{\mathrm{O}^{2-}}$ are the ionic radii of $\mathrm{Ba}^{2+}, \mathrm{Sr}^{2+}, \mathrm{Bi}^{3+}$, $\mathrm{Ti}^{4+}, \mathrm{Fe}^{3+}, \mathrm{Sm}^{3+}$ and $\mathrm{O}^{2-}$ respectively. The calculated value of ' $\mathrm{t}$ ' for $\mathrm{xBST}-(1-\mathrm{x}) \mathrm{BFSO}$ ceramics is listed in Table 1. Fig. 2 shows the variation of ' $t$ ' with BST content. The value of ' $t$ ' increases (from 0.846 to 0.877 ) with the addition of BST content, which indicates that the perovskite structure of xBST-(1-x)BFSO becomes more stable with increasing BST content. As the structure of BST is more stable than BFSO hence the overall stability increases with the addition of BST. 


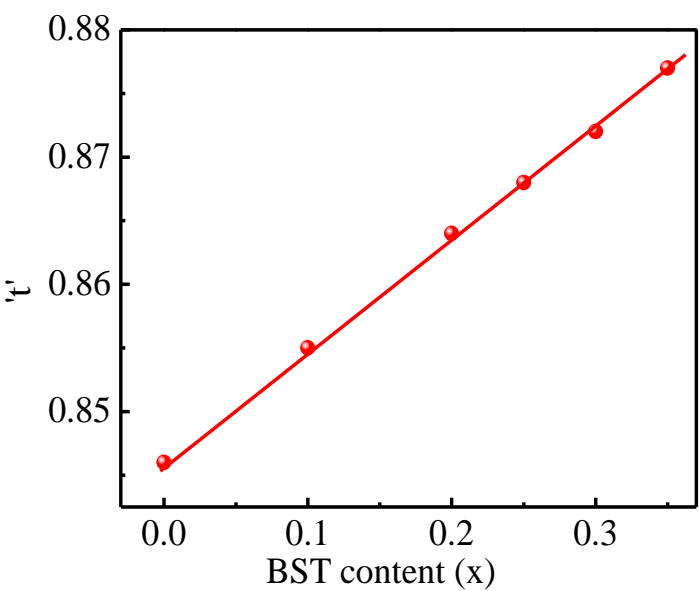

Fig. 2. Variation of ' $\mathrm{t}$ ' with BST content of various $\mathrm{xBST}-(1-\mathrm{x}) \mathrm{BFSO}$ ceramics.

Table 1: Crystal structure, lattice parameters (a and c), tolerance factor (' $\mathrm{t}$ ') and frequency exponent ('s') for various xBST-(1-x)BFSO ceramics.

\begin{tabular}{cccccc}
\hline Compositions $(\mathrm{x})$ & Structure & $\mathrm{a}(\AA)$ & $\mathrm{c}(\AA)$ & 't' & 's' \\
\hline 0.00 & Rhombohedral & 5.52 & 13.44 & 0.846 & 0.48 \\
0.10 & Rhombohedral & 5.56 & 13.48 & 0.855 & 0.61 \\
0.20 & Rhombohedral & 5.60 & 13.57 & 0.864 & 0.69 \\
0.25 & Cubic & 3.94 & - & 0.868 & 0.76 \\
0.30 & Cubic & 3.93 & - & 0.872 & 0.72 \\
0.35 & Cubic & 3.92 & - & 0.877 & 0.81 \\
\hline
\end{tabular}

\subsection{Dielectric properties}

Temperature dependent dielectric properties of various xBST-(1-x)BFSO $(\mathrm{x}=0.00,0.10,0.20$, $0.25,0.30$ and 0.35 ) ceramics are shown in Fig. 3 which are measured at $1 \mathrm{kHz}$ frequency. The value of $\varepsilon^{\prime}$ for all compositions is seen high compared to BFSO (x =0.00). Cubic-structured samples $(x \geq 0.25)$ exhibit greater value than the rhombohedral-structured $(x \leq 0.20)$ ceramics. The enhanced dielectric properties of the prepared samples are attained because of low oxygen vacancies when BST is added in BFSO. 

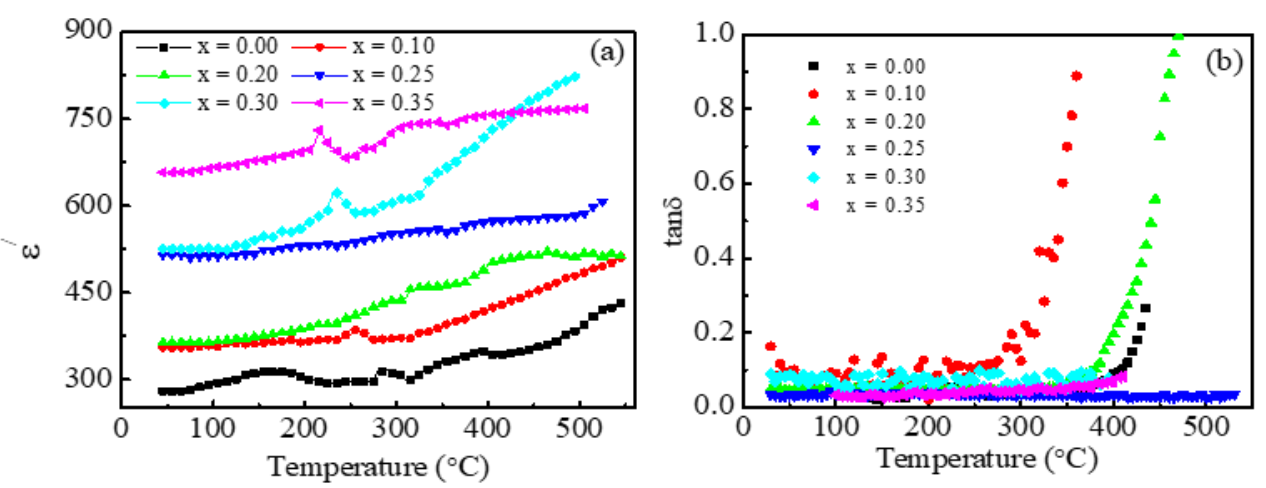

Fig. 3. Temperature dependent (a) $\varepsilon^{\prime}$ and (b) $\tan \delta$ of various xBST-(1-x)BFSO ceramics at $1 \mathrm{kHz}$.

As shown in Fig. 3(a), the value of $\varepsilon^{\prime}$ is found increasing with the increase in temperature. A doping compositional dependent distinct dielectric anomaly has also been observed within the range of temperatures $200-300{ }^{\circ} \mathrm{C}$ for all samples (except for $\mathrm{x}=0.25$ ) nearly close to the vicinity of the Néel temperature $\left(\mathrm{T}_{\mathrm{N}}\right)$ of $\mathrm{BFO}\left(\sim 270^{\circ} \mathrm{C}\right)$. Such anomaly was predicted by the Landau-Devonshire theory of phase transitions as a vanishing of magnetic order in the vicinity of $\mathrm{T}_{\mathrm{N}}$ in $\mathrm{BFO}$ based multiferroic materials [29]. Several authors also reported similar anomalies in the temperature dependent dielectric measurement for undoped and rare earth doped BFO [30, 31]. The value of transition temperature is noticed shifting to lower temperature side with the increase in BST substitution. The shift in $\mathrm{T}_{\mathrm{N}}$ can be correlated to the change in $\mathrm{Fe}-\mathrm{O}-\mathrm{Fe}$ bond angle due to the structural modification by the substitution of larger atoms $\mathrm{Ba}$ and $\mathrm{Sr}$ in $\mathrm{Bi}$-site and $\mathrm{Sm}$ and $\mathrm{Ti}$ in $\mathrm{Fe}$ site. Correlation of $\mathrm{T}_{\mathrm{N}}$ and bond angle is given by the relation, $T_{N}=J Z S(S+1) \cos \theta$, where $\mathrm{J}$ is the exchange constant, $\mathrm{S}$ is the spin of $\mathrm{Fe}^{3+}, \mathrm{Z}$ is the average linkages per $\mathrm{Fe}^{3+}$ ions and $\theta$ is the $\mathrm{Fe}-\mathrm{O}-$ Fe bond angle [32].

Fig. 3(b) presents the variation of $\tan \delta$ with temperature and it is seen that $\tan \delta$ remains almost constant at lower temperature region but it increases sharply with the rise in temperature (in the high-temperature region). Conduction of electric charges become accelerates at higher temperature because of thermally activated process and hence oxygen vacancies increase as well as $\tan \delta$ increase [33]. Compositional dependent anomalies are also noticed in the dielectric loss tangent of the samples and this may be attributed to the transient reaction between oxygen vacancies or due to transition in electric ordering [33, 34].

\subsection{Electrical conductivity}

Fig. 4(a) shows the variation of $\sigma_{\mathrm{AC}}$ with frequency of various xBST-(1-x)BFSO ceramics at room temperature. It is seen that the frequency dependence of $\sigma_{\mathrm{AC}}$ spectrum exhibit two different regions. At low frequency region, this corresponds to $\sigma_{\mathrm{dc}}$, the conductivity is almost independent of frequency. On the other hand, at high frequency region, which is known as hopping region; $\sigma_{\mathrm{AC}}$ increases faster than that of $\sigma_{\mathrm{dc}}$. At higher frequencies the conductive grains become more active thereby increases hopping of charge carriers and contribute to rise in conductivity. The frequency dependence of $\sigma_{\mathrm{AC}}$ of the xBST-(1-x) BFSO compound obey the Jonscher's power law [35] as given in Eq. (3): 

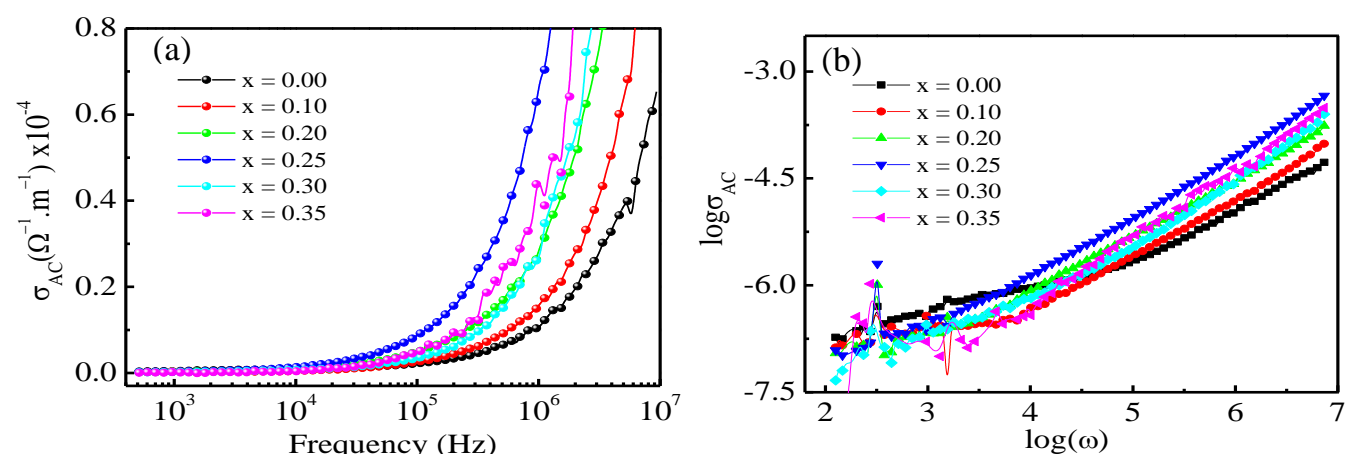

Fig. 4. (a) Variation of $\sigma_{\mathrm{AC}}$ with frequency and (b) plots of $\log \left(\sigma_{\mathrm{AC}}\right)$ versus $\log (\omega)$ of various $\mathrm{xBST}$ $(1-\mathrm{x}) \mathrm{BFSO}$ ceramics at room temperature.

$\sigma_{A C}(\omega)=\sigma_{d c}+B \omega^{s}$

where, $\sigma_{\mathrm{AC}}(\omega)$ is the total electrical conductivity, $\sigma_{\mathrm{dc}}$ is the frequency independent dc conductivity, $\mathrm{B}$ is the temperature dependent pre-exponential factor and ' $\mathrm{s}$ ' is the frequency exponent. The variation of $\sigma_{\mathrm{AC}}$ can also be explained by polaron hopping mechanism. In large polaron model, $\sigma_{\mathrm{AC}}$ decreases with the increase in frequency while in small polaron hopping mechanism, the $\sigma_{\mathrm{AC}}$ increases with the increase in frequency [36]. The enhancement of $\sigma_{\mathrm{AC}}$ with frequency is noticed for all compositions in Fig. 4(b) which implied that there is a small polaron hopping in the conduction mechanism of the studied compound. From the slope of $\log \left(\sigma_{\mathrm{AC}}\right)$ vs $\log (\omega)$ curves the value of frequency exponent ' $s$ ' is determined and it shows that the values are less than unity $(0.48<$ ' $s$ ' $<$ 0.81). All the values of ' $\mathrm{s}$ ' is presented in Table 1. It increases with the addition of BST in BFSO which indicates that diffusion limited hopping is involved in the present system. So, the transport mechanism would be explained by thermally activated hopping process between two sites which is separated by an energy barrier. Previously published articles on $\mathrm{Ba}^{2+}$ and $\mathrm{Gd}^{3+}$ doped $\mathrm{BFO}$ and $\mathrm{Mn}$ doped BT-BFO solid solution [37, 38] exhibited the similar results.

The temperature dependent $\sigma_{\mathrm{AC}}$ spectrum of $\mathrm{xBST}-(1-\mathrm{x}) \mathrm{BFSO}$ ceramics with $\mathrm{x}=0.00-0.25$ is shown in Fig. 5. In low frequency region, the $\sigma_{\mathrm{AC}}$ remains almost constant and $\sigma_{\mathrm{AC}}$ increases sharply in the high frequency region. The value of $\sigma_{\mathrm{AC}}$ is found increasing with the increase in temperature for all samples. On the other hand, the frequency independent $\sigma_{\mathrm{AC}}$ region is becoming broad with the rise in temperature. The polaron hopping electron between ions is mainly responsible for the electrical conductivity mechanism. With increasing temperature, the electron hopping between the ions becomes easier and hence the frequency independent $\sigma_{\mathrm{AC}}$ region becomes broader with the increase in temperature. As shown in Fig. 5, the value of $\sigma_{\mathrm{AC}}$ increases with increasing temperature, which indicates the normal behavior of semiconducting materials. At the high temperature region, the ceramics absorbed a large amount of heat energy which induces the mobility of charge carriers and this might be helped to increase $\sigma_{\mathrm{AC}}$ sharply [39]. On the other hand, it is suggested that hopping of electrons from the valance band to conduction band easily occurs at high temperature region because of reduction of band gap between the valance band and conduction band which provides high conductivity as compared to the low temperature region. 

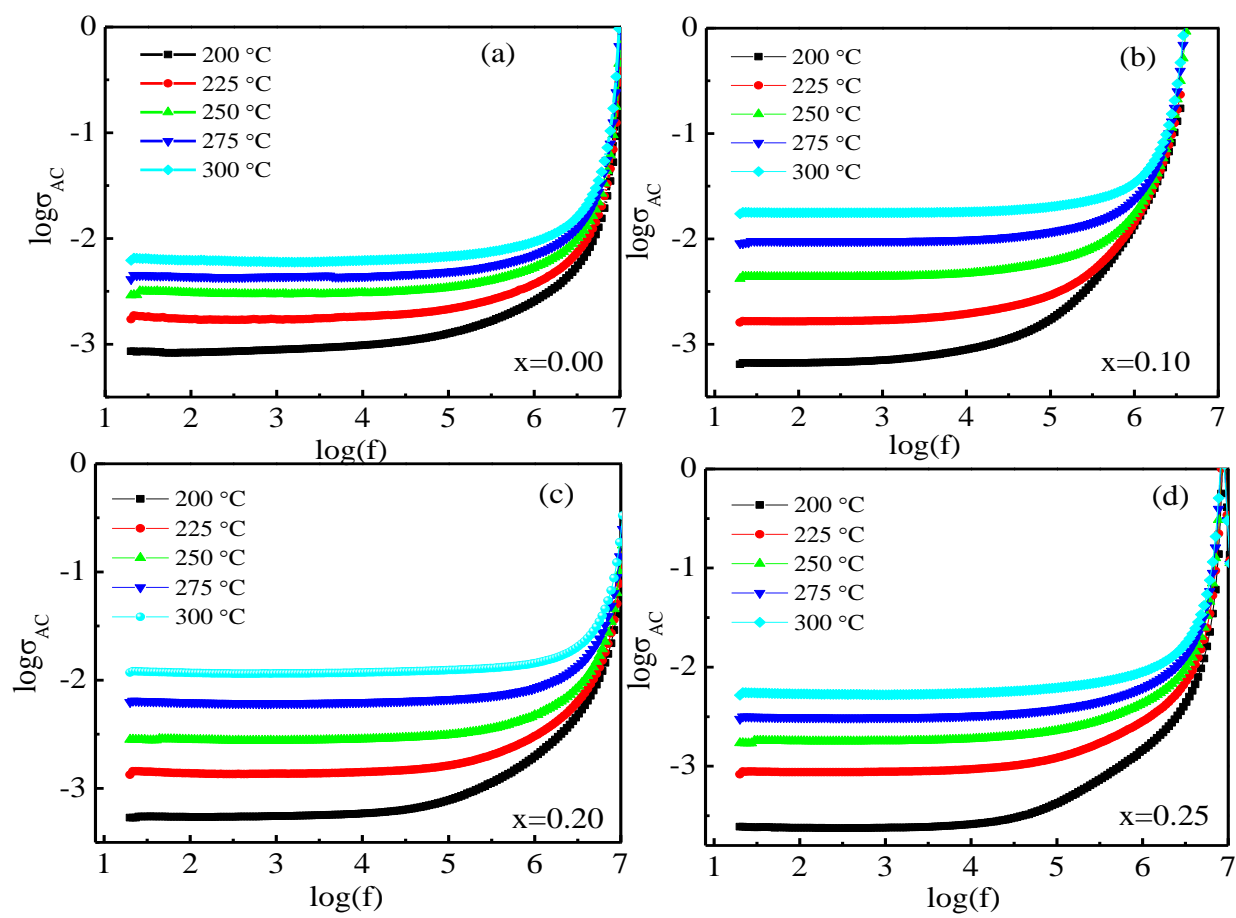

Fig. 5. Variation of $\sigma_{\mathrm{AC}}$ with frequency at different temperatures of various $x B S T-(1-\mathrm{x}) \mathrm{BFSO}$ ceramics: (a) $\mathrm{x}=0.00$, (b) $\mathrm{x}=0.10$, (c) $\mathrm{x}=0.20$ and (d) $\mathrm{x}=0.25$.

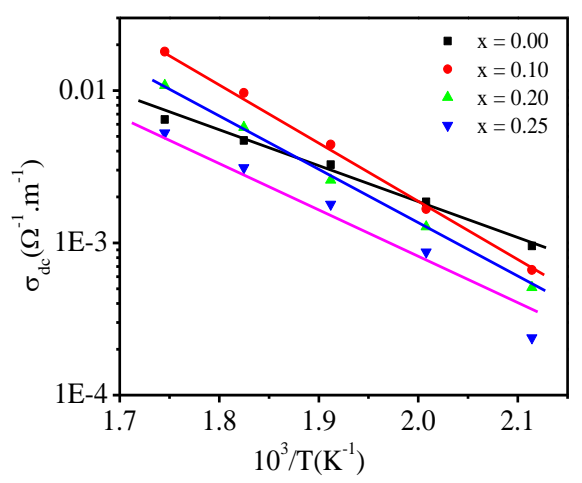

Fig. 6. Variation of $\sigma_{\mathrm{dc}}$ with inverse of temperature of various $\mathrm{xBST}-(1-\mathrm{x}) \mathrm{BFSO}$

Fig. 6 shows the variation of $\sigma_{\mathrm{dc}}$ with inverse of absolute temperature $\left(10^{3} / \mathrm{T}\right)$ of various xBST-(1$\mathrm{x}) \mathrm{BFSO}$ ceramics with $\mathrm{x}=0.00,0.10,0.20$ and 0.25 . The value of $\sigma_{\mathrm{dc}}$ is evaluated from the complex impedance plots of the sample at various temperatures $\left(200-300{ }^{\circ} \mathrm{C}\right)$. It is seen that the $\sigma_{\mathrm{dc}}$ increases (i.e., bulk resistivity decreases) with the rise in temperature and hence, the material shows negative 
temperature coefficient of resistance (NTCR) behavior like a semiconductor [40]. The nature of variation of $\sigma_{\mathrm{dc}}$ with temperature as shown in Fig. 6 is following the Arrhenius relation: $\sigma_{\mathrm{dc}}=\sigma_{0} \exp$ $\left(-\mathrm{E}_{\mathrm{a}} / \mathrm{K}_{\mathrm{B}} \mathrm{T}\right)$ where, $\sigma_{0}$ is the pre-exponential factor, $\mathrm{K}_{\mathrm{B}}$ is the Boltzmann constant and $\mathrm{E}_{\mathrm{a}}$ is the activation energy.

\subsection{Complex impedance}

\subsubsection{Complex impedance at room temperature}
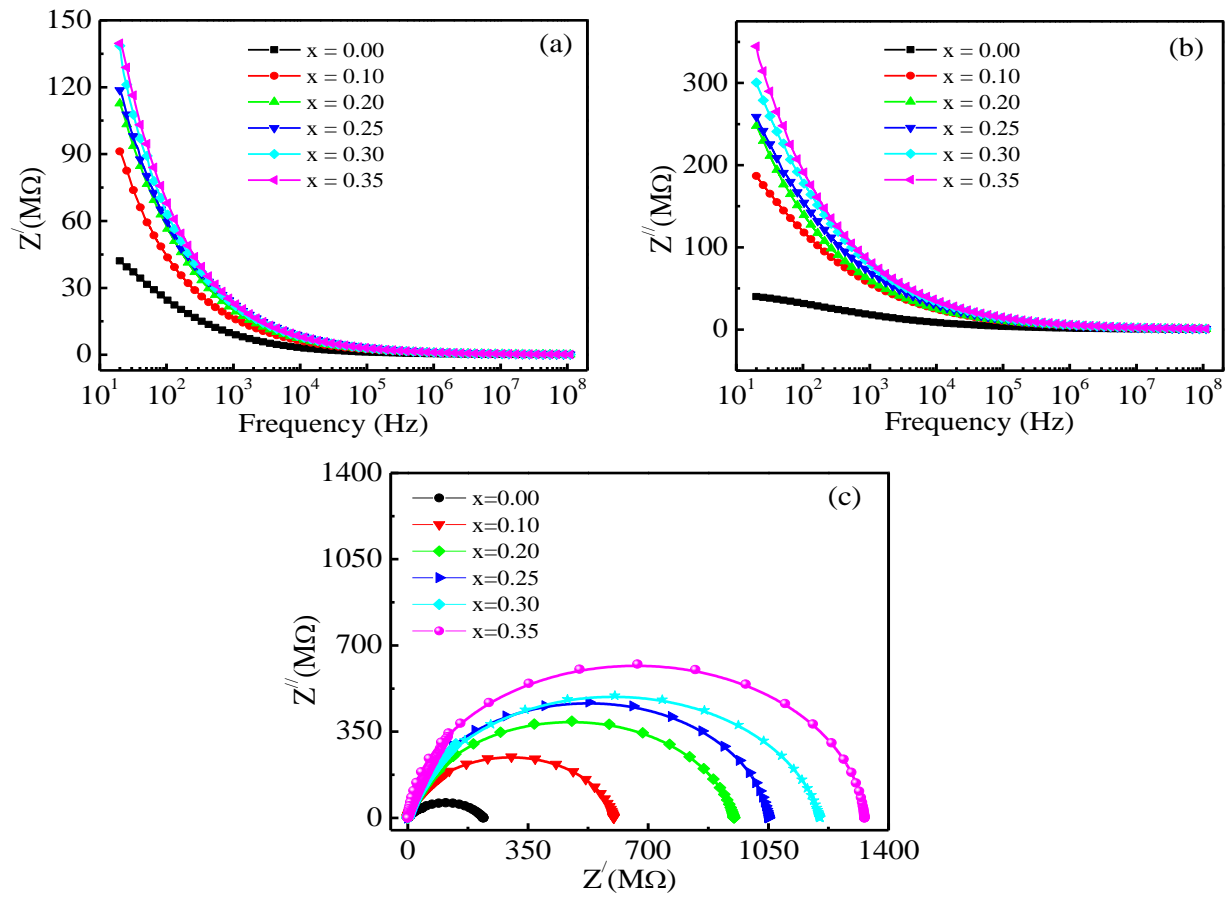

Fig. 7. Complex impedance spectra of various xBST-(1-x)BFSO ceramics: (a) $Z^{\prime}$ vs frequency plot, (b) $Z^{\prime \prime}$ vs frequency plot and (c) Cole - Cole plot ( $Z^{\prime}$ vs $Z^{\prime \prime}$ plot).

According to the classical model known as Debye model [41], impedance behavior of a compound is expressed by the equation:

$$
\begin{aligned}
Z^{*}(\omega) & =Z^{\prime}-j Z^{\prime \prime} \\
& =[1 / R+j \omega C]^{-1} \\
& =\left(R-j \omega R^{2} C\right) / 1+(\omega C R)^{2} \\
& =\left[R / 1+(\omega C R)^{2}\right]-j\left[R^{2} \omega C / 1+(\omega C R)^{2}\right]
\end{aligned}
$$


where, $\quad Z^{\prime}=R /\left[1+(\omega C R)^{2}\right]$ and $Z^{\prime \prime}=R^{2} \omega C /\left[1+(\omega C R)^{2}\right]$

$Z^{\prime}$ is the real and $Z^{\prime \prime}$ is the imaginary part of complex impedance $Z^{*}$. Fig. 7(a) shows the variation of $Z^{\prime}$ with frequency at room temperature for all compositions. It is observed that the value of $Z^{\prime}$ gradually decreases with increasing frequency up to a certain limiting frequency $\left(\approx 10^{5} \mathrm{~Hz}\right)$ and after this frequency $\left(\approx 10^{5} \mathrm{~Hz}\right)$ the variation of $Z^{\prime}$ shows frequency independent nature. At lower frequency region $Z^{\prime}$ have higher values which implied that the polarization in the ceramics is greater because all kinds of polarization can exist at lower frequencies. It is also noticed that the value of $Z^{\prime}$ for all compositions merge at higher frequencies which might be attributed to release of space charge at higher frequency [42,43]. The variation of $Z^{\prime \prime}$ with frequency (Fig. 7(b)) displays the same nature and no peak is observed for all compositions within the range of frequency of $20 \mathrm{~Hz}-120 \mathrm{MHz}$.

The plot of $Z^{\prime}$ vs $Z^{\prime \prime}$ (Cole-Cole plot) for different compositions of the studied compound at room temperature is shown in Fig. 7(c). A single semicircular arc starting from the origin is noticed for all compositions. No other semicircular arc is observed in the complex impedance plots which suggest that a contribution of grains in conduction mechanism of the studied compound is dominating. There is a change in the patterns of the semicircular arc with the variation of composition is also noticed which indicates a change in conductivity in the prepared samples. The diameter of the semicircular arc is becoming bigger with the increase in BST content. The value of resistance for the grain $\left(\mathrm{R}_{\mathrm{g}}\right)$ is determined from the intercepts on the real part of the $Z^{\prime}$ - axis and it shows that the value of $R_{g}$ is increasing with the increase in BST content. The number of nonconducting grain boundaries increase because of reducing grain size during the substitution of BST in BFSO and thus the value of $\mathrm{R}_{\mathrm{g}}$ is found to be enhanced with BST content.

\subsubsection{Temperature dependent complex impedance}

Fig. 8 illustrates the variation of $Z^{\prime}$ with frequency of various $\mathrm{xBST}-(1-\mathrm{x}) \mathrm{BFSO}(\mathrm{x}=0.00,0.10$, 0.20 and 0.25$)$ ceramics at different temperatures $\left(200-300{ }^{\circ} \mathrm{C}\right)$. It is seen that the value of $Z^{\prime}$ decreases with the rise in temperature in the low-frequency region and appears to merge in the highfrequency region. At higher frequencies, the variation of $Z^{\prime}$ is independent both on the frequency and temperature. On increasing temperature the value of $Z^{\prime}$ decreases at low frequency region which may be attributed to the reduction in barrier properties of the materials with the rise in temperature and responsible for the enhancement of conductivity [44]. 

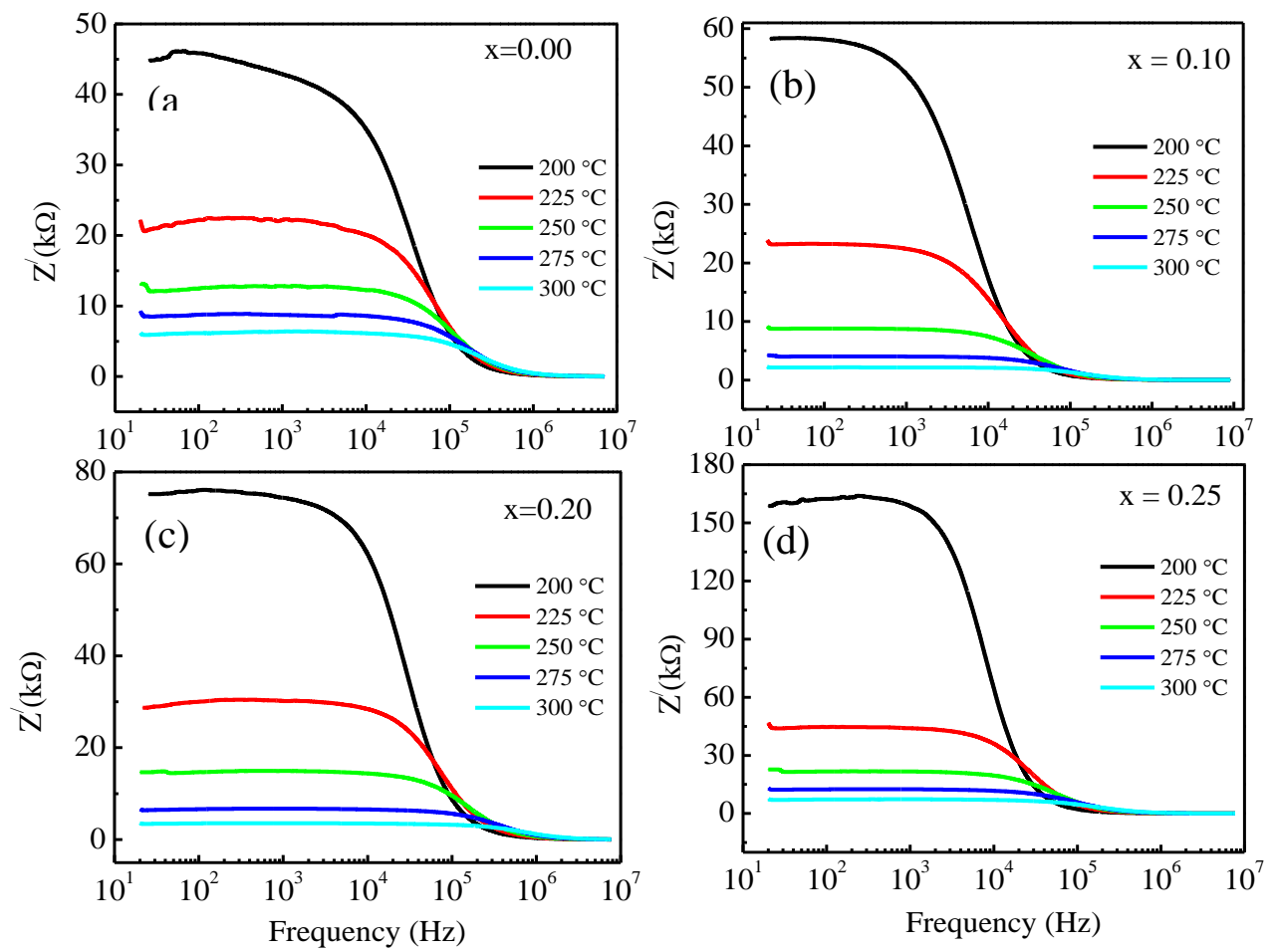

Fig. 8. Variation of $Z^{\prime}$ with frequency at different temperatures: (a) $x=0.00$, (b) $x=0.10$, (c) $\mathrm{x}=0.20$ and (d) $\mathrm{x}=0.25$.

Fig. 9 shows the variation of $Z^{\prime \prime}$ of various xBST-(1-x)BFSO compounds with frequency at different temperatures and it is seen that all compositions exhibit a peak. These peaks shift towards higher frequencies on increasing temperature in a broadening manner with the peak width. It indicates a thermally activated dielectric relaxation process in the materials. But these peaks are absent at room temperature (Fig. 7(b)) which may be due to the weak current dissipation in the material or peaks may lie beyond the frequency of measurement. The broadening of the peaks with the increase in temperature suggests the presence of temperature dependent dielectric relaxation in the materials. The asymmetric broadening of peaks has also been observed for the materials which suggest that non-Debye type relaxation process occurs in these materials. The dispersion curves appear to merge and this behavior is seen only at higher frequencies because of elimination of space charges at this frequency. $Z^{\prime \prime}$ is also found to depend on BST substitution to BFSO. An increasing trend of the peak height is exhibited with the increase in BST content which implied that the charge carriers face strong barrier to move within the grains. 

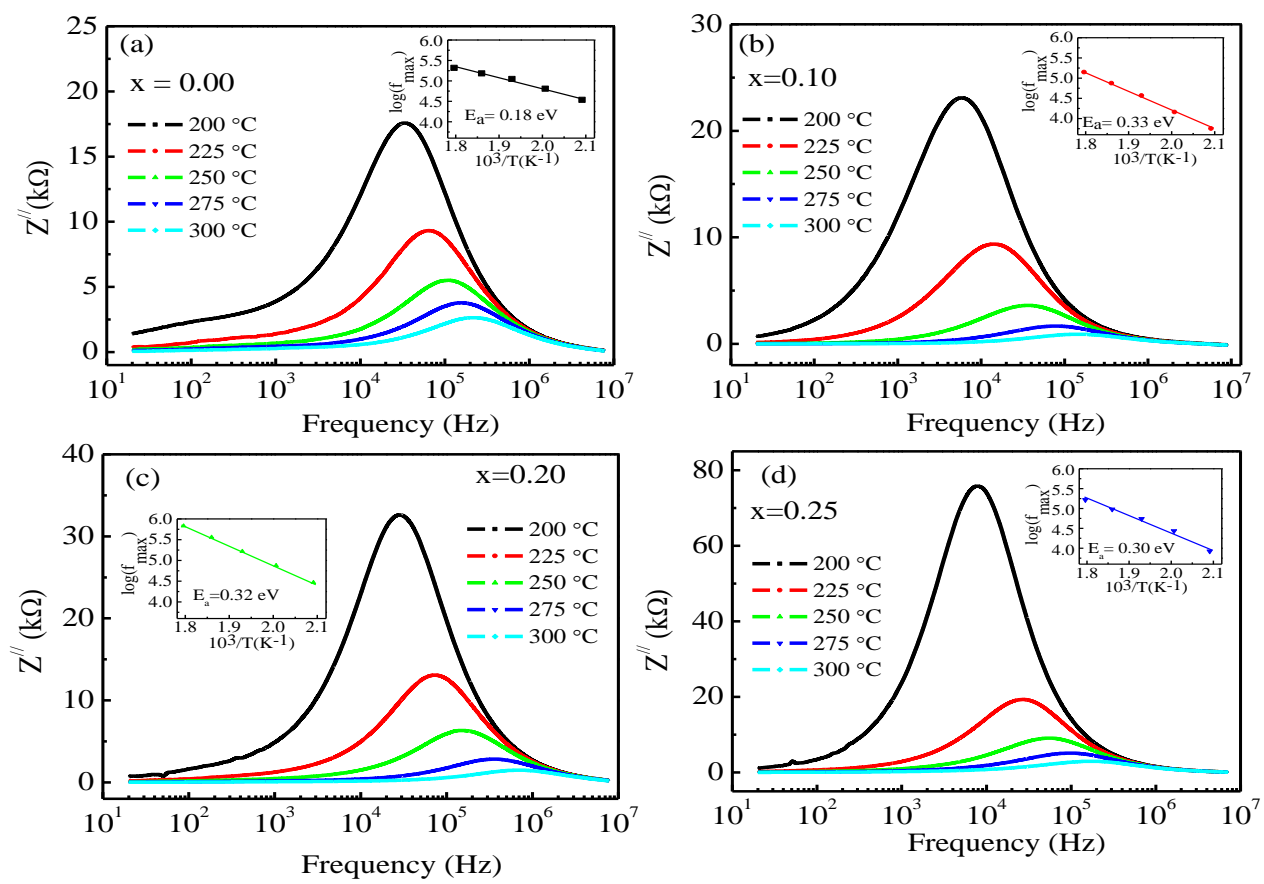

Fig. 9. Variation of $Z^{\prime \prime}$ with frequency at different temperatures: (a) $x=0.00$, (b) $x=0.10$, (c) $x=0.20$ and (d) $x=0.25$. [Inset shows $\log \left(f_{\max }\right) v s 10^{3} / T$ plot for various compositions]

It is obvious that width of the peak is broadening with the change in temperature (Fig. 9) i.e. there is a non-Debye type relaxation is existed in the prepared materials. The relaxation frequency $\left(f_{\mathrm{r}}\right)$ is determined from the frequency versus $Z^{\prime \prime}$ curves (Fig. 9) and the values of $f_{\mathrm{r}}$ for different temperatures of various xBST-(1-x)BFSO ceramics are listed in Table 2. The dependence of $f_{\mathrm{r}}$ on temperature can be described by the Arrhenius relation: $f_{r}=f_{o} \exp \left(-E_{a} / K_{B} T\right)$, where, $f_{\mathrm{o}}$ is the pre-exponential factor, $K_{B}$ is the Boltzmann constant, $E_{a}$ is the activation energy for the hopping mechanism and $T$ is the absolute temperature. The variation of $f_{r}$ with temperature is presented at the inset of Figure 9. From the slope of $f_{r}$ vs temperature curves the values of $E_{a}$ are determined and found to be $0.18 \sim 0.33 \mathrm{eV}$.

The complex impedance spectra ( $Z^{\prime}$ vs $Z^{\prime \prime}$ plot) of various xBST-(1-x)BFSO ceramics at different temperatures $\left(200-300{ }^{\circ} \mathrm{C}\right)$ is shown in Fig. 10. Single semicircular arcs have been observed for all the compositions. The absence of second semicircle in the complex impedance plots suggests the dominance of grain contributions in the conduction mechanism of xBST- $(1-x)$ BFSO ceramics. The semicircles are also found to be depressed with their center which confirms the existence of nonDebye type relaxation in the compounds. It is also observed that the intercept point on the real axis shifts toward the origin with the increase in temperature which indicates the reduction of resistive property. The values of $\mathrm{R}_{\mathrm{g}}$ are determined for different compositions and these are listed in Table 2. It is noticed that the value of $\mathrm{R}_{\mathrm{g}}$ for each of the xBST-(1-x)BFSOcompositions exhibit decreasing 
trend with the increase in temperature which supports the typical negative temperature coefficient of resistance behavior of the materials usually shown by semiconductor.

Table 2: The values of grain resistance $\left(\mathrm{R}_{\mathrm{g}}\right)$ and grain capacitance $\left(\mathrm{C}_{\mathrm{g}}\right)$ of various $\mathrm{xBST}-(1-\mathrm{x}) \mathrm{BFSO}$ ceramics at different temperatures.

\begin{tabular}{lllll}
\hline xBST-(1-x)BFSO & Temp. $\left({ }^{\circ} \mathrm{C}\right)$ & $\mathrm{R}_{\mathrm{g}}(\Omega)$ & $\mathrm{C}_{\mathrm{g}}(\mathrm{F})$ & $\mathrm{f}_{\mathrm{r}}(\mathrm{kHz})$ \\
\hline 0.00 & 200 & $4.321 \times 10^{4}$ & $1.070 \times 10^{-10}$ & 34.421 \\
& 225 & $2.223 \times 10^{4}$ & $1.110 \times 10^{-10}$ & 64.464 \\
& 250 & $1.267 \times 10^{4}$ & $1.125 \times 10^{-10}$ & 111.621 \\
275 & $8.791 \times 10^{3}$ & $1.185 \times 10^{-10}$ & 152.753 \\
& 300 & $6.394 \times 10^{3}$ & $1.191 \times 10^{-10}$ & 209.043 \\
& & & & \\
0.10 & 200 & $5.837 \times 10^{4}$ & $4.449 \times 10^{-10}$ & 5.668 \\
& 225 & $2.319 \times 10^{4}$ & $4.725 \times 10^{-10}$ & 14.526 \\
& 250 & $8.758 \times 10^{3}$ & $4.883 \times 10^{-10}$ & 37.230 \\
& 275 & $4.007 \times 10^{3}$ & $5.268 \times 10^{-10}$ & 75.412 \\
0.20 & 300 & $2.148 \times 10^{3}$ & $5.247 \times 10^{-10}$ & 141.231 \\
& & & & \\
& 200 & $7.595 \times 10^{4}$ & $7.124 \times 10^{-11}$ & 29.425 \\
& 225 & $3.031 \times 10^{4}$ & $6.965 \times 10^{-11}$ & 75.412 \\
& 250 & $1.495 \times 10^{4}$ & $6.443 \times 10^{-11}$ & 165.216 \\
0.25 & 275 & $6.750 \times 10^{3}$ & $6.517 \times 10^{-11}$ & 361.962 \\
& 300 & $3.578 \times 10^{3}$ & $6.564 \times 10^{-11}$ & 677.877 \\
& & & & \\
& 200 & $1.634 \times 10^{5}$ & $1.161 \times 10^{-10}$ & 8.38942 \\
& 225 & $4.462 \times 10^{4}$ & $1.311 \times 10^{-10}$ & 27.2049 \\
& 250 & $2.169 \times 10^{4}$ & $1.332 \times 10^{-10}$ & 55.1058 \\
& 275 & $1.247 \times 10^{4}$ & $1.337 \times 10^{-10}$ & 95.4168 \\
& 300 & $7.376 \times 10^{3}$ & $1.306 \times 10^{-10}$ & 165.216 \\
\hline
\end{tabular}

\subsection{Complex modulus at different temperatures}

The complex electric modulus is represented by the following expression:

$$
\begin{aligned}
& M^{*}(\omega)=j\left(\omega C_{o}\right) Z * \\
& =M^{\prime}+j M^{\prime \prime} \\
& =\omega C_{o} Z^{\prime \prime}+j \omega C_{o} Z^{\prime}
\end{aligned}
$$

where, $\quad M^{\prime}=\omega C_{o} Z^{\prime \prime}$

and

$$
M^{\prime \prime}=\omega C_{o} Z^{\prime}
$$



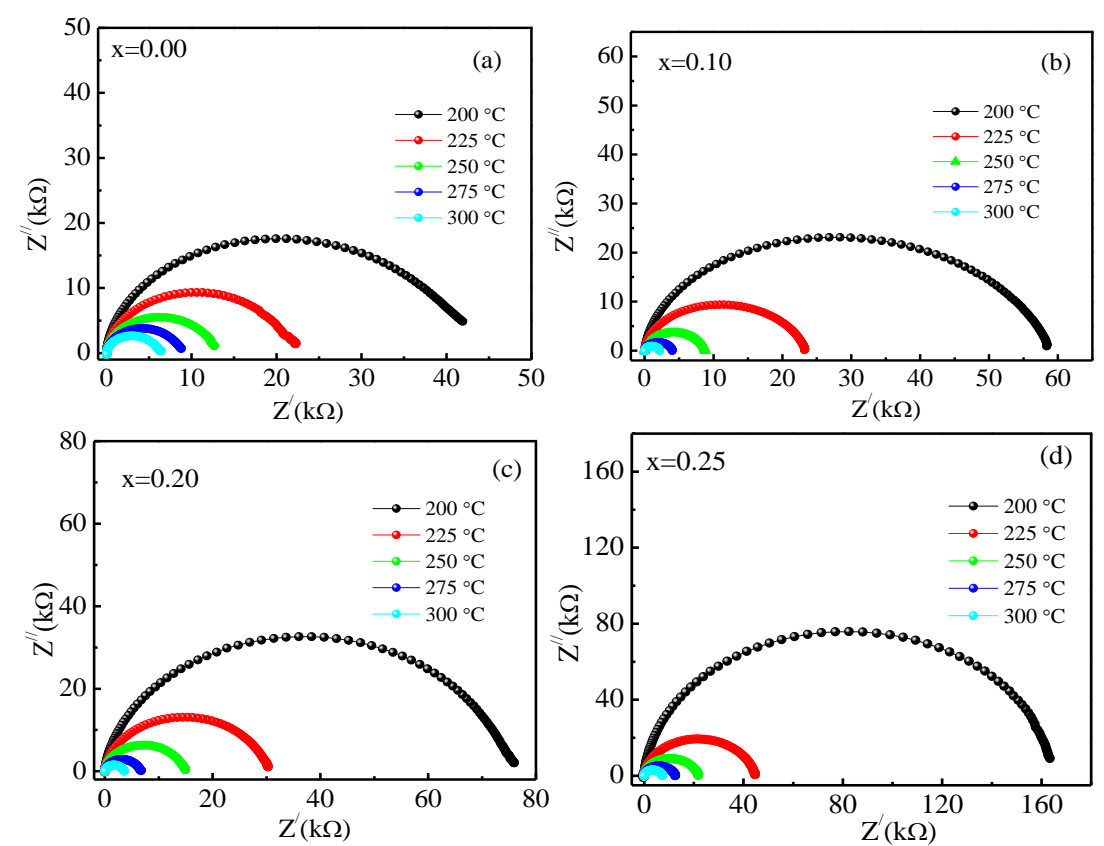

Fig. 10. Complex impedance spectra $\left(Z^{\prime}\right.$ vs $Z^{\prime \prime}$, Cole-Cole plot) of various xBST-(1$\mathrm{x}) \mathrm{BFSO}$ ceramics at different temperatures.

$M^{\prime}$ is the real and $M^{\prime \prime}$ is the imaginary part of complex modulus. The variation of $M^{\prime}$ as a function of frequency for xBST-(1-x)BFSO ceramics at different temperatures is shown in Fig. 11. At low frequency region $M^{\prime}$ have very small value (nearly zero). It shows increasing trend with the increase in frequency up to a certain limiting frequency and then it again decreases. The variation of $M^{\prime}$ that shows in Fig. 11 may be attributed to short range mobility of charge carriers which contribute to the conduction phenomenon. It perhaps makes a relationship with the lack of restoring force leading the mobility of the charge carriers under the action of an induced electric field [45]. It is also found that the dispersion region shifts towards higher frequency side. The merger of $M^{\prime}$ observed at lower frequencies suggests about the frequency invariant electrical properties ( $\mathrm{dc}$ conductivity) of the materials.

Fig. 12 shows the variation of $M^{\prime \prime}$ of various xBST-(1-x)BFSO ceramics with frequency at different temperatures $\left(200-300{ }^{\circ} \mathrm{C}\right)$. It exhibits a peak for each of the composition at all temperatures and the peaks are shifting towards higher frequency side with the increase in temperature. The peaks indicate a transition from long range to short-range mobility with an increase in frequency. At low frequency the ions are capable of moving a long distance (i.e. performing successful hopping from one site to the neighboring site). At high frequency side of the peak, the ions are spatially confined to their potential wells and can execute only localized motion within the well. A shifting of the peaks 
toward higher frequency side is noticed which indicates that the dielectric relaxation is a thermally activated process in the materials as mentioned for the case of impedance analysis. Asymmetry in peak broadening is also observed for the material which suggests that the relaxation is of non-Debye type. The relaxation frequency $\left(f_{\max }\right)$ for various compositions is determined from the $M^{\prime \prime}$ vs frequency curves. The plot of $f_{\max }$ vs temperature curves is shown at the inset of Fig 12. The temperature dependence of $\mathrm{f}_{\max }$ curves follow the Arrhenius relation: $f_{r}=f_{o} \exp \left(-E_{a} / K_{B} T\right)$, where the symbols have their using meanings. From the slope of $f_{\max }$ vs temperature curves, the value of $E_{a}$ has been calculated and it is found to be 0.18 to $0.32 \mathrm{eV}$ for various compositions. The estimated values are found to be nearly close to the values of $E_{a}$ obtained from impedance spectra which suggests that the mobility of charge carrier in the prepared samples is occurred due to the same mechanism.
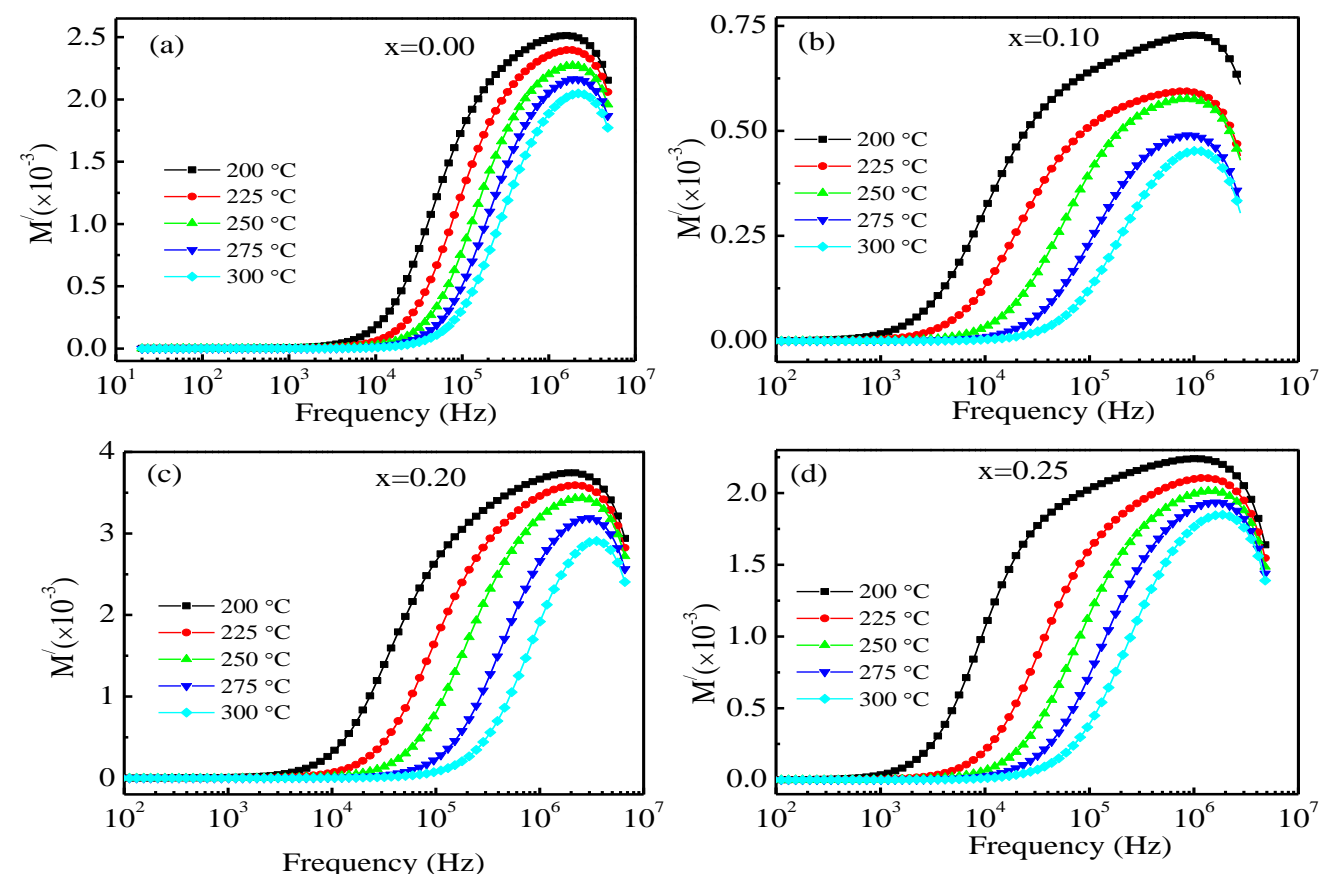

Fig. 11. Variation of $\mathrm{M}^{\prime}$ with frequency of various $x B S T-(1-\mathrm{x}) \mathrm{BFSO}$ ceramics at different temperatures: (a) $\mathrm{x}=0.00$, (b) $\mathrm{x}=0.10$, (c) $\mathrm{x}=0.20$ and (d) $\mathrm{x}=0.25$. 

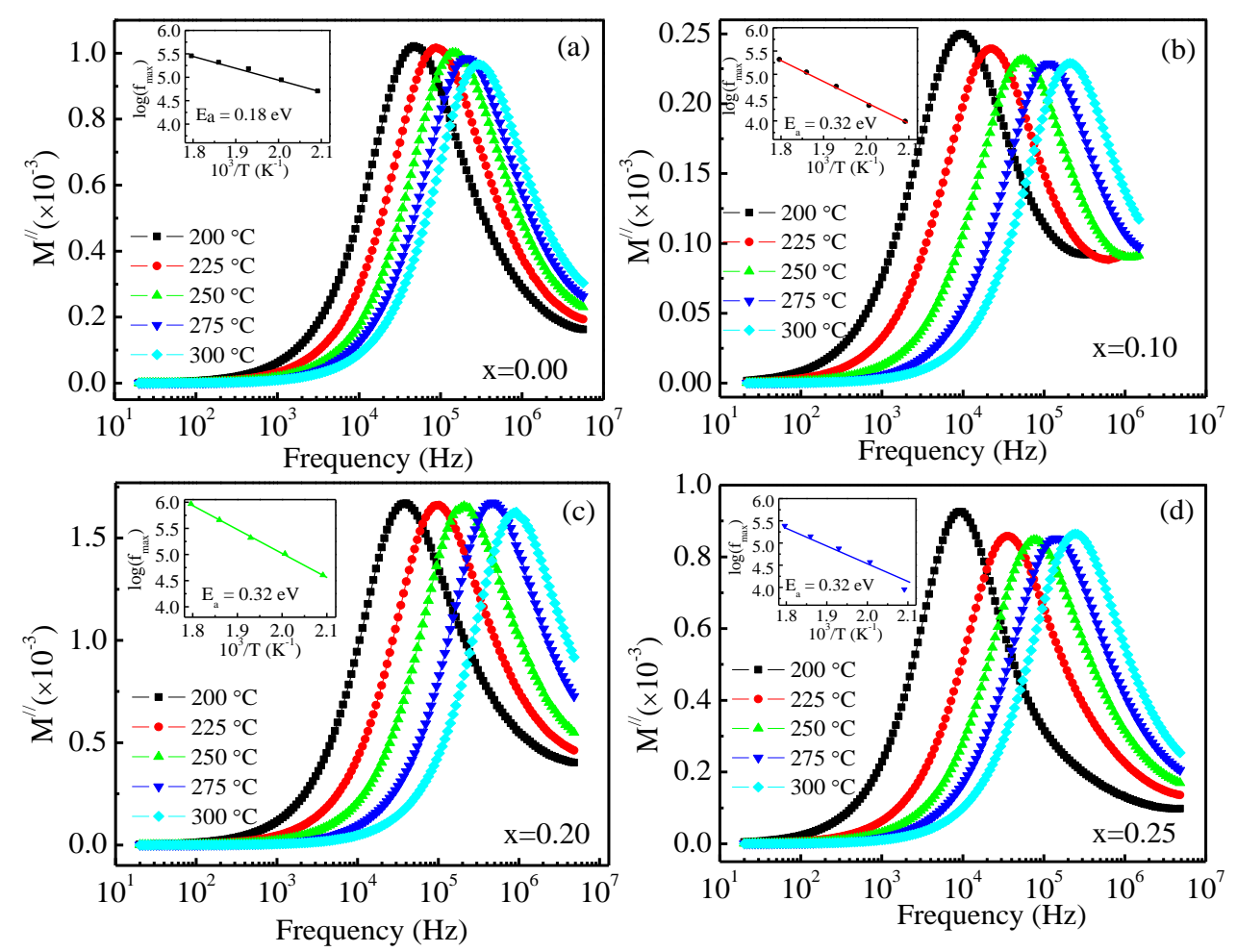

Fig. 12. Variation of $M^{\prime \prime}$ with frequency of various $x B S T-(1-x) B F S O$ ceramics at different temperatures: (a) $\mathrm{x}=0.00$, (b) $\mathrm{x}=0.10$, (c) $\mathrm{x}=0.20$ and (d) $\mathrm{x}=0.25$. [Inset shows $\log \left(f_{\max }\right)$ vs $10^{3} / \mathrm{T}$ plot for various compositions]

Fig. 13 shows the complex modulus spectra $\left(M^{\prime}\right.$ vs $\left.M^{\prime \prime}\right)$ of various xBST-(1-x)BFSO ceramics with $\mathrm{x}=0.00-0.25$ at different temperatures $\left(200-300{ }^{\circ} \mathrm{C}\right)$. The impedance data are re-plotted in the modulus formula because of removing the confusion arising out about the contribution of grain/grain boundary effect in the conduction mechanism of the compound. There is a change in the shape of modulus spectra with the rise in temperature is observed which indicate a probable variation in the conductivity as a function of temperature. As shown of Fig. 13, all the curves also exhibit a single semicircular arc like impedance spectra (Fig. 10) which support the information obtained from the impedance plot about major contribution of grain in conduction mechanism of the studied compound. 

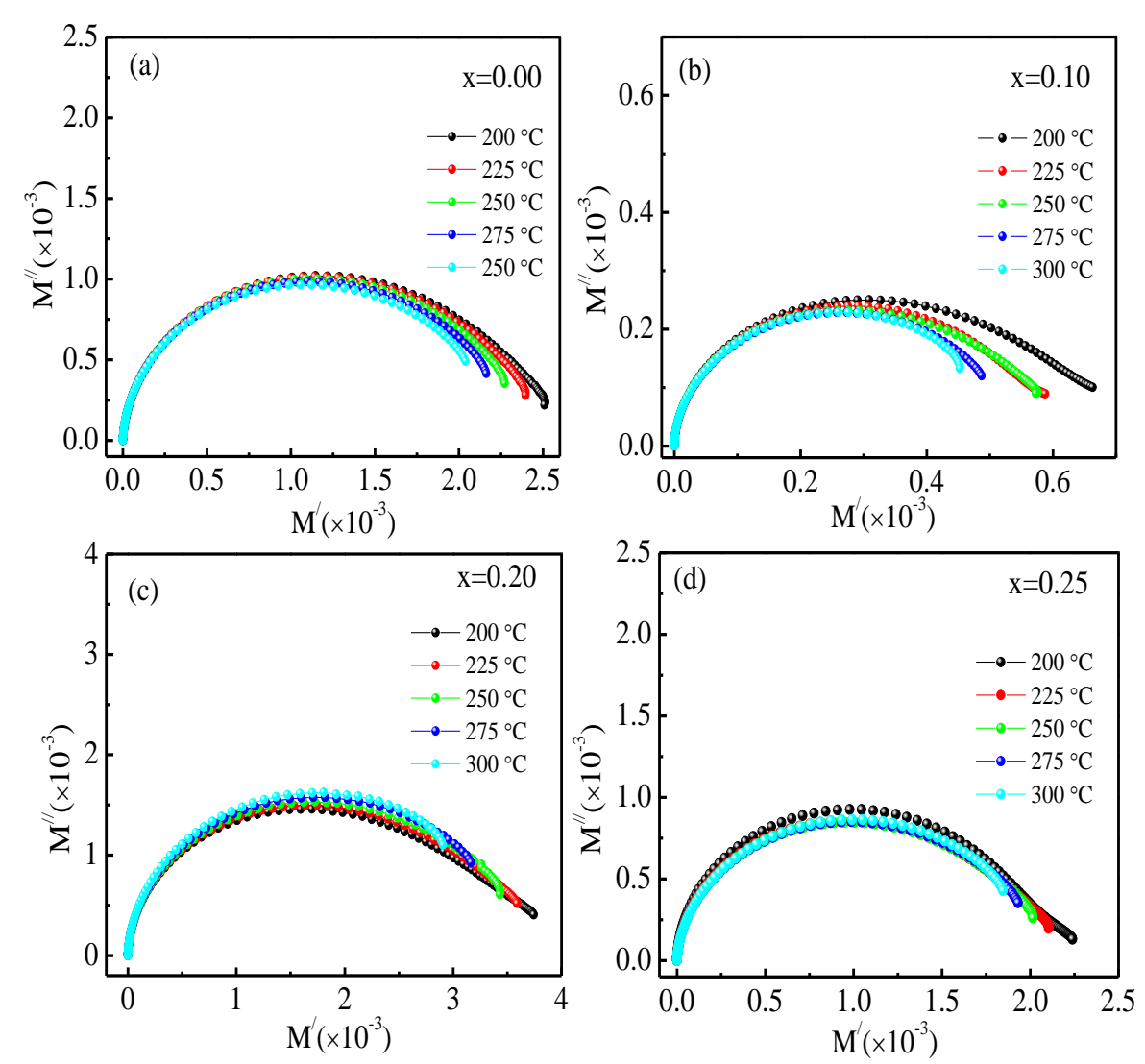

Fig. 13. Variation of $\mathrm{M}^{\prime /}$ with $\mathrm{M}^{\prime}$ of various $\mathrm{xBST}-(1-\mathrm{x}) \mathrm{BFSO}$ ceramics at different temperatures: (a) $\mathrm{x}=0.00$, (b) $\mathrm{x}=0.10$, (c) $\mathrm{x}=0.20$ and (d) $\mathrm{x}=0.25$.

\section{CONCLUSIONS}

Various xBST-(1-x)BFSO ceramics were prepared by the conventional solid state reaction technique. Crystal structure, tolerance factor, temperature dependent dielectric property, AC conductivity and temperature dependent complex impedance measurement were carried out. The compositions showed rhombohedral distorted perovskite structure for $\mathrm{x}=0.00-0.20$ and transformed to cubic structure for $\mathrm{x} \geq 0.25$. Structural stability was observed with the addition of BST because of higher value of tolerance factor of BST than BFSO. The dielectric constant was found to be enhanced with increasing BST content in BFSO due to the increased space charge polarization at the grain boundaries and a dielectric anomaly close to $\mathrm{T}_{\mathrm{N}}\left(=273^{\circ} \mathrm{C}\right)$ of $\mathrm{BFO}$ were exhibited. The AC conductivity reduced with the increase in temperature. The values of frequency exponent ('s') were found less than unity $(0.48<$ 's' $<0.81)$ and raised with the increase in BST. Studies of complex impedance spectroscopy suggested that grains had the major contribution to the conduction mechanism in this material. The value of grain resistance decreased with increasing 
temperature which implied that the ceramics had semiconducting behavior with negative temperature coefficient of resistance (NTCR). The values of activation energies were found to be 0.18 to $0.33 \mathrm{eV}$ in complex impedance analysis and nearly equal values were noticed from complex modulus analysis. The analysis of the electric modulus at different temperatures confirmed the major contribution of grains in the compound. The results may be helpful for the applications of the studied compound in high performance electrical devices.

\section{ACKNOWLEDGEMENTS}

The authors greatly acknowledge the CASR, Bangladesh University of Engineering and Technology (BUET), Bangladesh to provide financial support for this research. One of the authors M. J. Miah thanks to the Ministry of National Science, Information \& Communication Technology (NST), Government of the People's Republic of Bangladesh for providing fellowship.

\section{REFERENCES}

[1] Zhai, J., Cai, N., Shi, Z., Lin, Y., Nan, C.W., Magnetic-dielectric properties of $\mathrm{NiFe}_{2} \mathrm{O}_{4} / \mathrm{PZT}$ particulate composites, J. Phys. D: Appl. Phys., 37, 823-827, 2004.

[2] Wang, J., Neaton, J. B., Zheng, H., Nagarajan, V., Ogale, S. B., Liu, B., Viehland, D., Vaithyanathan, V., Schlom, D. G., Waghmare, U. V., Spaldin, N. A., Rabe, K. M., Wuttig, M., Ramesh, R., Epitaxial $\mathrm{BiFeO}_{3}$ multiferroic thin film heterostructures, Science, 299, 1719-1722, 2003.

[3] Sosnowska, I., Neumaier, P. T., Steichele, E., Spiral magnetic ordering in bismuth ferrite, J. Phys. C: Solid State Phys., 15, 4835-4846, 1982.

[4] Eerenstein, W., Mather, N. D., Scott, J. F., Multiferroic and magnetoelectric materials, Nature, 442, 759765, 2006.

[5] Kumar, M. M., Shrinivas, A., Suryanarayana, S.V., Structure property relations in $\mathrm{BiFeO}_{3} / \mathrm{BaTiO}_{3}$ solid solutions, J. Appl. Phys., 87, 855, 2000.

[6] Kumar, M. M., Srinath, S., Kumar, G. S., Suryanarayana, S. V., Spontaneous magnetic moment in $\mathrm{BiFeO}_{3}-\mathrm{BaTiO}_{3}$ solid solutions at low temperatures, J. Magn. Magn. Mater., 188, 203-212, 1998.

[7] Tian, Z. M., Zhang, Y. S., Yuan, S. L., Wu, M. S., Wang, C. H., Ma, Z. Z., Huo, S. X., Duan, H. N., Enhanced multiferroic properties and tunable magnetic behavior in multiferroic $\mathrm{BiFeO}_{3}-\mathrm{Bi}_{0.5} \mathrm{Na}_{0.5} \mathrm{TiO}_{3}$ solid solution, Mat. Sci. Eng. B, 177, 74-78, 2012.

[8] Verma, K. C., Kotnala, R. K., Multiferroic magnetoelectric coupling and relaxor ferroelectric behavior in 0.7 $\mathrm{BiFeO}_{3}-0.3 \mathrm{BaTiO}_{3}$ nanocrystals, Solid State Commun., 151, 920-923, 2011.

[9] Li, C. X., Yang, B., Zhang, S. T., Zang, R., Sun, Y., Zang, H. J., Cao, W. W., Enhanced multiferrioc and magnetocapacitive properties of $(1-\mathrm{x}) \mathrm{Ba}_{0.7} \mathrm{Ca}_{0.3} \mathrm{TiO}_{3}-\mathrm{xBiFeO}$ ceramics, J. Am. Ceram. Soc., 97, 816$825,2014$.

[10] Cai, W., Zhong, S., Fu, C., Chen, G., Deng, X., Microstructure, dielectric and ferroelectric properties of $\mathrm{xBaZr}_{0.2} \mathrm{Ti}_{0.8} \mathrm{O}_{3}-(1-\mathrm{x}) \mathrm{BiFeO}_{3}$ solid solution ceramics, Mater. Res. Bull., 50, 259-267, 2014.

[11] Yu, B., Li, M., Hu, Z., Pei, L., Guo, D., Zhao, X., Dong, S., Enhanced multiferroic properties of the highvalence Pr doped BiFeO3 thin film, Appl. Phy. Lett., 93, 09182909, 2008.

[12] Khomchenko, V. A., Shvartsman, V. V., Borisov, P., Kleemann, W., Kiselev, D. A., Bdikin, I. K., Vieira, J. M., Kholkin, A. L., Effect of Gd substitution on the crystal structure and multiferroic properties of $\mathrm{BiFeO}_{3}$, Acta Mater., 57, 5137-5145, 2009.

[13] Nguyen, V. M., Nguyen, G. Q., Structural, optical and electromagnetic properties of $\mathrm{Bi}_{1-x} \mathrm{Ho}_{\mathbf{x}} \mathrm{FeO}_{3}$ multiferroic materials, J. Alloys Compd., 509, 2663-2666, 2009.

[14] Zhang, S., Luo, W., Wang, D., Ma, Y., Phase evolution and magnetic property of $\mathrm{Bi}_{1-\mathrm{x}} \mathrm{Dy}_{\mathrm{x}} \mathrm{FeO}_{3}$ ceramics, Mater. Lett., 63, 1820-1822, 2009. 
[15] Bhushan, B., Basumallick, A., Bandopadhyay, S. K., Vasanthacharya, N. Y., Das, D., Effect of alkaline earth metal doping on thermal, optical, magnetic and dielectric properties of $\mathrm{BiFeO}_{3}$ nanoparticles, $\mathrm{J}$. Phys. D, 42, 065004-065011, 2009.

[16] Kumar, M., Yadav, K. L., Study of room temperature magnetoelectric coupling in Ti substituted bismuth ferrite system, J. Appl. Phys., 100, 074111, 2006.

[17] Chauhan, S., Kumar, M., Chhoker, S., Katyal, S. C., Singh, H., Jewariya, M., Yadav, K. L., Multiferroic, magnetoelectric and optical properties of $\mathrm{Mn}$ doped $\mathrm{BiFeO}_{3}$ nanoparticles, Solid State Commun., 152, 525,2012

[18] Miah, M. J., Khan, M. N. I., Hossain, A. K. M., Weak ferromagnetism and magnetoelectric effect in multiferroic xBa0.95 $\mathrm{Sr}_{0.05} \mathrm{TiO}_{3}-(1-\mathrm{x}) \mathrm{BiFe}_{0.9} \mathrm{Gd}_{0.1} \mathrm{O}_{3}$ relaxors, J. Magn. Magn. Mater., 401, 600-611, 2016.

[19] Miah, M. J., Khan, M. N. I., Hossain, A. K. M., Synthesis and enhancement of multiferroic properties of xBa $0.95 \mathrm{Sr}_{0.05} \mathrm{TiO}_{3}-(1-\mathrm{x}) \mathrm{BiFe}_{0.9} \mathrm{Dy}_{0.1} \mathrm{O}_{3}$ ceramics, J. Magn. Magn. Mater., 397, 39-50, 2016.

[20] Hodge, I. M., Ingram, M. D., West, A. R, Impedance and modulus spectroscopy of polycrystalline solid electrolytes, J. Electroanal. Chem., 74, 125, 1976.

[21] Hsu, C.Y., Chou, H., Liao, B.Y., Huang, J. C. A., Interfacial and quantum well effects on ac impedance of $\mathrm{La}_{0.7} \mathrm{Sr}_{0.3} \mathrm{MnO}_{3} / \mathrm{La}_{1.4} \mathrm{Sr}_{1.6} \mathrm{Mn}_{2} \mathrm{O}_{7}$ composites, Appl. Phys. Lett., 89, 26250, 2006.

[22] Das, S. R., Choudhary, R. N. P., Bhattacharya, P., Katiyar, R. S., Dutta, P., Manivannan, A. and Seehra, M. S., Structural and multiferroic properties of La- modified $\mathrm{BiFeO}_{3}$ ceramics, J. Appl. Phys., 101, 034104:1-4, 2007.

[23] Uniyal, P., Lotey, G. S., Gautam, A., Verma, N. K. and Yadav, K. L., Multiferroic properties of $\left(\mathrm{Bi}_{0.9} \mathrm{Gd}_{0.1} \mathrm{FeO}\right)_{1-\mathrm{x}-}\left(\mathrm{BaTiO}_{3}\right)_{\mathrm{x}}$ ceramics, J. Supercond. Novel Magn., 27, 569-574, 2014.

[24] Ma, Z. Z., Tian, Z. M., Li, J. Q., Wang, C. H., Huo, S. X., Duan, H. N. and Yuan, S. L., Enhanced polarization and magnetization in multiferroic $(1-\mathrm{x}) \mathrm{BiFeO}_{3}-\mathrm{xSrTiO}_{3}$ solid solution, Solid State Sci., 13 , 2196-2200, 2011.

[25] Kumar, M., Shankar, S., Parkash, Om and Thakur, O. P., Dielectric and multiferroic properties of $0.75 \mathrm{BiFeO}_{3}-0.25 \mathrm{BaTiO}_{3}$ solid solution, J. Mater. Sci: Mater. Electron., 25, 888-894, 2014.

[26] Zhang, H., Wook, J., Wang, K. and Webber, K. G., Compositional dependence of dielectric and ferroelectric properties in $\mathrm{BiFeO}_{3}-\mathrm{BaTiO}_{3}$ solid solutions, Ceram. Int., 40, 4759-4765, 2014

[27] Denton, A. R. and Ashcroft, A. W., Vegrad's law, J. Phys. Rev. A, 43, 4161-4164, 1991.

[28] Goldschmidt, V. M., The laws of crystal chemisty, Naturwissenschaften, 14, 477-485, 1926.

[29] Benguigui, L., Thermodynamic theory of the morphotropic phase transition tetragonal-rhombohedral in the perovskite ferroelectrics, Solid State Commun., 11, 825-828, 1972.

[30] Zhang, L.Y., Zhang, J., Chang, Y. F., Yuan, G. L., Yang, B. and Zhang, S. T., Composition dependent microstructures and properties of $\mathrm{La}, \mathrm{Zn}$ and $\mathrm{Cr}$ modified $0.675 \mathrm{BiFeO}_{3}-0.325 \mathrm{BaTiO}_{3}$ ceramics, J. Am. Ceram. Soc., 99, 2989-2994, 2016.

[31] Muneeswaran, M. and Giridharan, N. V., Effect of Dy- substitution on the structural, vibrational and multiferroic properties of $\mathrm{BiFeO}_{3}$ nanoparticles, J. Appl. Phys., 115, 214109, 2014.

[32] Sati, P. C., Kumar, M. and Chhoker, S., Low temperature ferromagnetic ordering and dielectric properties of $\mathrm{Bi}_{1-\mathrm{x}} \mathrm{Dy}_{\mathrm{x}} \mathrm{FeO}_{3}$ ceramics, Ceram. Int., 41, 3227-3236, 2015.

[33] Singh, H. and Yadav, K. L., Synthesis and thermal, structural, dielectric, magnetic and magnetoelectric studies of $\mathrm{BiFeO}_{3}-\mathrm{MgFe}_{2} \mathrm{O}_{4}$ nanocomposites, J. Am. Ceram. Soc., 98, 574-579, 2015.

[34] Mish, R. K., Pradhan, D. K., Choudhary, R. N. P. and Banerjee, A., Effect of yttrium on improvement of dielectric properties and magnetic switching behavior in $\mathrm{BiFeO}_{3}$, J. Phys.: Condens. Matter., 20, 045218, 2008.

[35] Jonscher, A. K., The universal dielectric response, Nature, 267, 673-679, 1977.

[36] Khandekar, M. S., Kambale, R. C., Patil, J. Y., Kolekar, Y. D. and Suryavanshi, S. S., Effect of calcination temperature on the structural and electrical properties of cobalt ferrite synthesized by combustion method, J. Alloys Compd., 509, 1861-1865, 2011.

[37] Das, R., Sarkar, T. and Mandal, K.,Multiferroic properties of $\mathrm{Ba}^{2+}$ and $\mathrm{Gd}^{3+}$ co-doped bismuth ferrite: magnetic, ferroelectric and impedance spectroscopic analysis, J. Phys. D: Appl. Phys., 45, 455002455011,2012 
[38] Sahni, M., Kumar, N., Singh, S., Jha, A., Chaubey, S., Kumar, M. and Sharma, M. K., Influence of Mn doping on structural, electrical and magnetic properties of $(0.90) \mathrm{BiFeO}_{3}-(0.10) \mathrm{BaTiO}_{3}$ composite, $\mathrm{J}$. Mater. Sci: Mater. Electron, 25, 2199-2209, 2014.

[39] Tominaga, T., Asai, S., Sumita, M., Panero, S. and Scrosati, B., A novel composite polymer electrolyte: effect of mesoporous $\mathrm{SiO}_{2}$ on ionic conduction in poly (ethylene oxide)- $\mathrm{LiCF}_{3} \mathrm{SO}_{3}$ complex, J. Power Source, 146, 402-406, 2005.

[40] Ranjan, R., Kumar, R., Kumar, N., Behera, B. and Choudhary, R. N. P., Impedance and electric modulus analysis of $\mathrm{Sm}$ - modified $\mathrm{Pb}\left(\mathrm{Zr}_{0.55} \mathrm{Ti}_{0.45}\right)_{1-x / 4} \mathrm{O}_{3}$ ceramics, J. Alloys Compd., 509, 6388-6394, 2011.

[41] Cao, W. and Gerhardt, R., Calculation of various relaxation times and conductivity for a single dielectric relaxation process, Solid State Ion., 42, 213-221, 1990.

[42] Behera, B., Nayak, P. and Choudhary, R. N. P., Structural and electrical properties of $\mathrm{KCa}_{2} \mathrm{Nb}_{5} \mathrm{O}_{15}$ ceramic, Cent. Eur. J. Phys., 6, 289-295, 2008.

[43] Plocharski, J. and Wieczoreck, W., PEO based composite solid electrolyte containing nasicon, Solid State Ion., 28-30, 979-982, 1988.

[44] Provenzano, V., Boesch, L. P., Volterra, V., Moynihan, C. T. and Macedo, P. B., Electrical relaxation in $\mathrm{Na}_{2} \mathrm{O}_{3} \mathrm{SiO}_{2}$ glass, J. Am. Cerm. Soc., 55, 492-496, 1972.

[45] Macedo, P. B., Moynihan, C. T. and Bose, R., Role of ionic diffusion in polarization in various ionic conductors, Phys. Chem. Glasses, 13, 171-179, 1972. 